\title{
Accuracy of Fnac in Diagnosing Thyroid Nodules: A Single Institution Experience
}

\author{
Ajay Kumar B*, Sreejayan MP and Vaisagh Remin \\ Department of General Surgery, Government Medical College, India
}

Received: August 23, 2017; Published: September 13, 2017

*Corresponding author: Ajay Kumar B, Assistant Professor, Department of General Surgery, Government Medical College, Kerala, India

\begin{abstract}
Background: FNA is the first-line investigation in the diagnosis of thyroid nodules.

Aims: To determine the accuracy of FNAC in diagnosing thyroid nodules.

To identify the major cause of discrepancy in FNAC reports

Methods: The final histopathology report (HPR) of all thyroidectomies done from January 2008 to December 2010 was retrieved by a retrospective search in institutional databases. Corresponding FNAC reports were also retrieved. The correlation between FNAC and final histopathology was studied to determine the accuracy with which FNAC diagnosed thyroid disorders.

Results: The sensitivity and specificity of FNAC in diagnosing benign nodules is $92 \%$ and $71.6 \%$ respectively.

A. The sensitivity and specificity of FNAC for diagnosis of neoplasm is $81.6 \%$ and $92 \%$ respectively.

B. The sensitivity and specificity of FNAC for diagnosis of malignancy is $87.8 \%$ and $98.2 \%$ respectively.

Conclusion: FNA is highly sensitive and specific in the diagnosis of thyroid nodules. Cytological similarities between hyperplasic nodule and follicular neoplasm are a major source of error.
\end{abstract}

Keywords: FNAC; Thyroid nodule; Follicular neoplasm; Malignancy

Abbreviations: TBSRTC: The Bethesda System for Reporting Thyroid Cytopathology; HPR: Histopathology Report; FVPCT: Follicular Variant of Papillary Carcinoma

\section{Introduction}

FNAC is the mostappropriate investigation to define the nature of a thyroid nodule and decide about the need for surgical intervention [1-3]. Taking in to consideration the need for standardization, the Bethesda System for Reporting Thyroid Cyto pathology (TBSRTC) was proposed and has been accepted worldwide [4,5]. This study was carried out with the aim of identifying the accuracy of FNAC in diagnosing thyroid nodules by comparing the final histopathology report of patients who had undergone thyroidectomy with their pre-operative FNAC.

\section{Objectives}

a. To determine the accuracy of FNAC in diagnosing thyroid nodules.

b. To identify the major cause of discrepancy in FNAC reports.

\section{Materials And Methods}

\section{Study Design}

Descriptive cross-sectional study.

\section{Study Setting}

Government Medical College Kozhikode, S4 unit.

\section{Study Period}

January 2008 to December 2010.

\section{Study Group}

All male and female patients who underwent thyroidectomies.

\section{Methodology}

The final histopathology report (HPR) of all thyroidectomies done from January 2008 to December 2010 was retrieved by a retrospective search in institutional databases. Corresponding 
FNAC reports were also retrieved. The HPR was divided into 3 main categories: Benign and non-neoplastic, Benign and neoplastic, and Malignant, each having several subcategories (Table 1). The FNAC report was also divided into 3: Benign (including nodular goiter and lymphocytic thyroiditis), Follicular neoplasm, Malignant (Table 2). The correlation between FNAC and final histopathology was studied to determine the accuracy with which FNAC diagnosed thyroid disorders.

Table 1: Distribution of histological categories.

\begin{tabular}{|c|c|c|}
\hline Histological type & Histological subtype & $\begin{array}{c}\text { Number (and \%) of } \\
\text { cases }\end{array}$ \\
\hline \multirow{2}{*}{$\begin{array}{c}\text { Benign and Non-Neo } \\
\text { Plastic }\end{array}$} & Nodular goiter & $190(73.1 \%)$ \\
\cline { 2 - 3 } & $\begin{array}{c}\text { Lymphocytic } \\
\text { thyroiditis }\end{array}$ & $10(3.8 \%)$ \\
\hline \multirow{2}{*}{$\begin{array}{c}\text { Benign and Neo } \\
\text { Plastic }\end{array}$} & Follicular adenoma & $14(5.4 \%)$ \\
\cline { 2 - 3 } Malignant & Hurthle cell adenoma & $5(1.9 \%)$ \\
\hline & Follicular carcinoma & $6(2.3 \%)$ \\
\cline { 2 - 3 } & Hurthle cell carcinoma & $2(0.8 \%)$ \\
\cline { 2 - 3 } & Papillary carcinoma & $32(12.3 \%)$ \\
\cline { 2 - 3 } & Ana plastic carcinoma & $1(0.4 \%)$ \\
\hline
\end{tabular}

The correlation between cytological and histological diagnoses is given in (Table 3). Hurthle cell adenoma has been included with follicular adenoma and hurtle cell carcinoma with follicular carcinoma. Of the 260 patients included in the study, $192 \mathrm{had}$ a benign (Bethesda II) diagnosis by FNA. Of the 192 cytologies

\section{Results}

A total of 260 patients were studied, which included 211 female patients and 49 male patients (female: male $=4.3: 1$ ). Age of the patients ranged from 17 years to 72 years (mean \pm standard deviation: $40 \pm 12$ years) (Table 1 ). The distributions of initial cytological diagnoses according to Bethesda categories were as follows: benign - 192 (73.8\%) including 189 cases of nodular goiter and 3 cases of lymphocytic thyroiditis, follicular neoplasm - 35(13.5\%) including 27 of follicular cell type and 8 of hurtle cell type, malignant-33(12.7\%) including 32 cases of papillary carcinoma and 1 case of undifferentiated (Ana plastic) carcinoma (Table 2).

Table 2: Pre-operative FNAC reports.

\begin{tabular}{|c|c|}
\hline FNAC & No. of patients \\
\hline Nodular goiter & 189 \\
\hline Lymphocytic thyroiditis & 3 \\
\hline Follicular neoplasm & 35 \\
\hline Papillary carcinoma & 32 \\
\hline Ana plastic carcinoma & 1 \\
\hline Total & $\mathbf{2 6 0}$ \\
\hline
\end{tabular}

that were reported as benign, 95.8\% (nodular goiter-92.7\% and lymphocytic thyroiditis-3.1\%) were confirmed to be benign by histopathology. Of the benign cytologies, $2.6 \%$ turned out to be follicular adenoma, $1 \%$ was papillary carcinoma and $0.5 \%$ was follicular carcinoma on histopathological examination (Table 3).

Table 3: Comparing cytology with histology.

\begin{tabular}{|c|c|c|c|c|c|c|c|}
\hline \multicolumn{7}{|c|}{ Histological diagnosis: number of patients } \\
\hline $\begin{array}{c}\text { Cytological } \\
\text { diagnosis }\end{array}$ & No. of patients & Nodular goiter & $\begin{array}{c}\text { Lymphocytic } \\
\text { thyroiditis }\end{array}$ & $\begin{array}{c}\text { Follicular } \\
\text { adenoma }\end{array}$ & $\begin{array}{c}\text { Follicular } \\
\text { carcinoma }\end{array}$ & $\begin{array}{c}\text { Papillary } \\
\text { carcinoma }\end{array}$ & $\begin{array}{c}\text { Ana plastic } \\
\text { carcinoma }\end{array}$ \\
\hline Benign & 192 & $178(92.7 \%)$ & $6(3.1 \%)$ & $5(2.6 \%)$ & $1(0.5 \%)$ & $2(1 \%)$ & 0 \\
\hline $\begin{array}{c}\text { Follicular neo } \\
\text { plasia }\end{array}$ & 35 & $11(31.4 \%)$ & $2(5.7 \%)$ & $13(37.1 \%)$ & $7(20 \%)$ & $2(5.7 \%)$ & 0 \\
\hline Malignant & 33 & $1(3 \%)$ & $2(6 \%)$ & $1(3 \%)$ & 0 & $28(84.8 \%)$ & $1(3 \%)$ \\
\hline Total & $\mathbf{2 6 0}$ & $\mathbf{1 9 0}$ & $\mathbf{1 0}$ & $\mathbf{1 9}$ & $\mathbf{8}$ & $\mathbf{3 2}$ & $\mathbf{1}$ \\
\hline
\end{tabular}

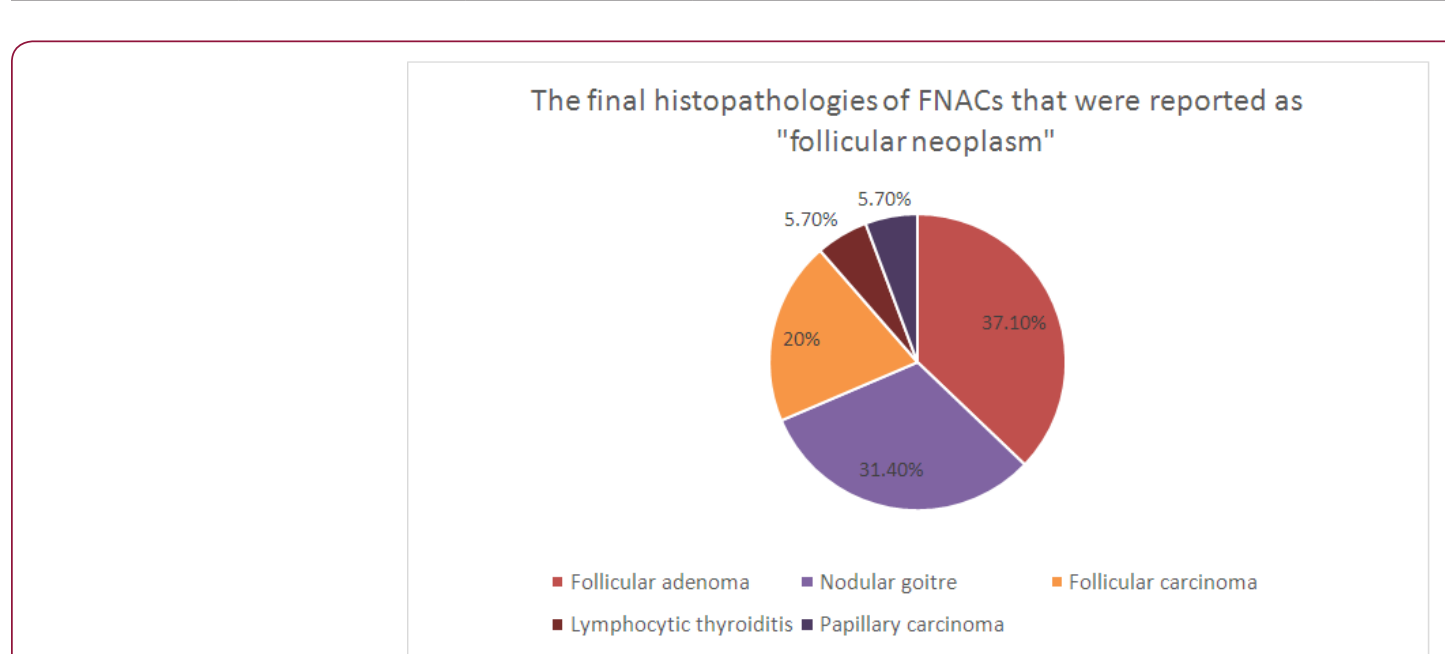

Figure 1: Final Histopathology of FNACs reported as 'Follicular Neoplasm'. 
This puts the positive predictive value of FNAC in diagnosing benign nodules (nodular goiter and lymphocytic thyroiditis) at $95.8 \%$. The sensitivity of FNAC in diagnosing benign nodules is $92 \%$ and specificity is $71.6 \%$. FNAC in 35 patients yielded the report of follicular neoplasia. On histology, $57.1 \%$ of these were follicular neoplasm's (follicular adenoma-37.1\% and follicular carcinoma-20\%). 37.1\% were benign (nodular goiter - 31.4\% and lymphocytic thyroiditis-5.7\%). Another 5.7\% turned out to be papillary carcinoma (Figure 1). The sensitivity and specificity of FNAC for diagnosis of follicular neoplasm was $74.1 \%$ and $93.5 \%$ respectively. The positive predictive value is $57.1 \%$ and the negative predictive value is $96.8 \%$.

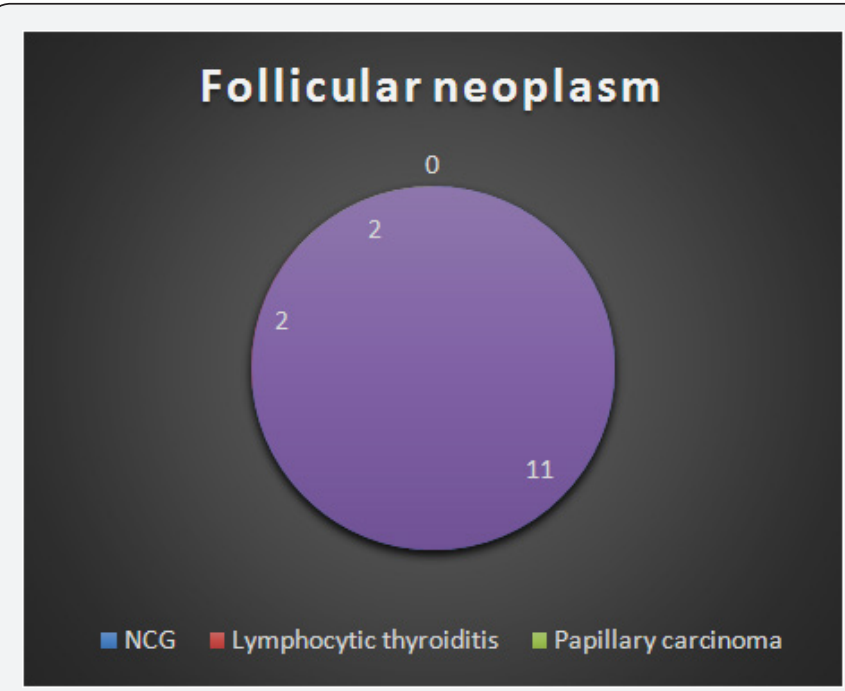

Figure 2: Distribution of final HPR in case of wrong FNA report of follicular neoplasm.

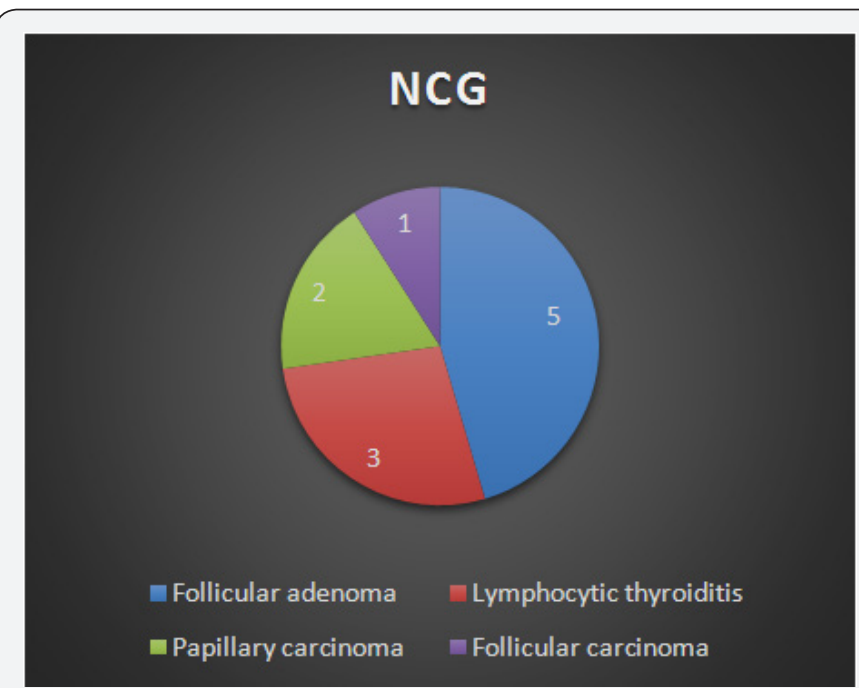

Figure 3: Distribution of final HPR in case of wrong FNA report of NCG.

33 cytologies were reported as malignant. In this group, $87.8 \%$ ultimately turned out to be malignant while $12.2 \%$ were benign. Sensitivity of FNA for diagnosis of malignancy is $87.8 \%$ and the specificity of FNA for diagnosis of malignancy is $98.2 \%$. The sensitivity and specificity of FNA for diagnosis of neoplasm (considering follicular adenoma and carcinoma along with malignancy) is $81.6 \%$ and $92 \%$ respectively. The benign and nonneo plastic histological type affected 167 females and 33 males. Benign and neoplastic group had 15 females and 4 males. Among the malignant group, 30 were female and 11 were male. Malignancy rate in males was $22.4 \%$ and in females was $14.2 \%$. The main cause of discrepancy was difficulty in differentiating between follicular adenoma and hyperplastic nodule (nodular goiter) (Table 4), (Figure 2-4).

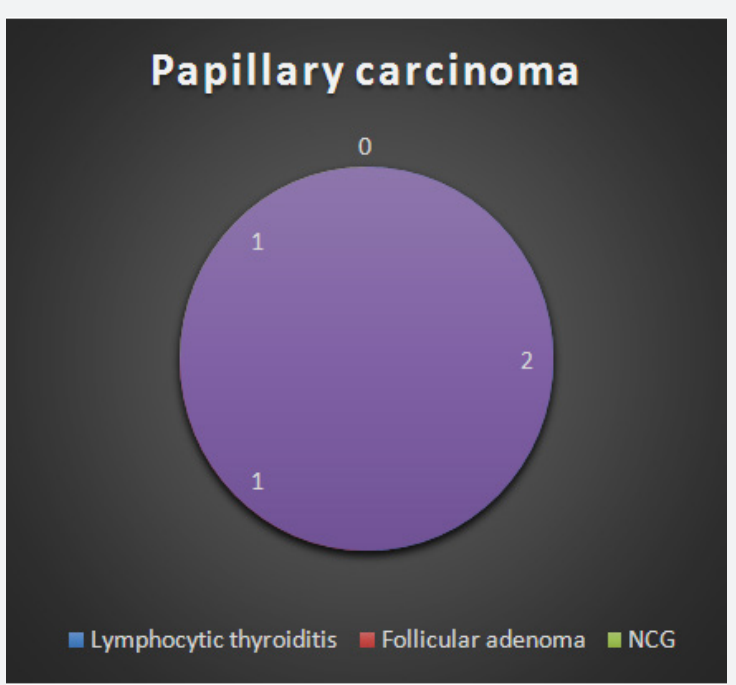

Figure 4: Distribution of final HPR in case of wrong FNA report of papillary carcinoma.

Table 4: Wrong FNA reports.

\begin{tabular}{|c|c|c|}
\hline FNAC & HPR & $\begin{array}{l}\text { Total number of } \\
\text { wrong reports }\end{array}$ \\
\hline Follicular neoplasm & NCG & 11 \\
\hline Follicular neoplasm & $\begin{array}{l}\text { Lymphocytic } \\
\text { thyroiditis }\end{array}$ & 2 \\
\hline Follicular neoplasm & Papillary carcinoma & 2 \\
\hline NCG & Follicular adenoma & 5 \\
\hline NCG & $\begin{array}{l}\text { Lymphocytic } \\
\text { thyroiditis }\end{array}$ & 3 \\
\hline NCG & Papillary carcinoma & 2 \\
\hline NCG & Follicular carcinoma & 1 \\
\hline Papillary carcinoma & $\begin{array}{l}\text { Lymphocytic } \\
\text { thyroiditis }\end{array}$ & 2 \\
\hline Papillary carcinoma & Follicular adenoma & 1 \\
\hline Papillary carcinoma & NCG & 1 \\
\hline
\end{tabular}

\section{Discussion}

The importance of thyroid nodules lies in the fact that although most nodules are benign, they may be the first sign of malignancy [6]. In the evaluation of patients with thyroid nodules, FNA has been accepted world over as the first-line screening test. FNA helps to decide whether a patient requires surgery or whether conservative management will suffice. A diagnosis of neoplasia or malignancy by FNA will necessitate surgery while benign lesions can be kept under follow up [7]. Several studies have put to test the accuracy 
of FNA by calculating the sensitivity and specificity with which it diagnosed thyroid nodules. Most of the studies reported sensitivity and specificity of $80 \%-100 \%$ for Thyroid FNAs [7]. In the present study, sensitivity and specificity of FNA for diagnosis of malignancy is $87.8 \%$ and $98.2 \%$ respectively. The sensitivity and specificity of FNA for diagnosis of neoplasm is $81.6 \%$ and $92 \%$ respectively.

Of the 30 FNA reports that turned out to be wrong in this study, 17 involved misdiagnoses between nodular goiter and follicular neoplasm (FN). Because of their cytological similarities, distinguishing between hyperplasic (adenomatous) nodule and follicular neoplasm (FN) is difficult and has been the subject of many studies [8-10]. Cytologically, it is difficult to differentiate hyperplastic nodule from so-called macro follicular adenoma or simple adenoma [7].

That said, some cytologic features that may help in distinguishing a hyperplastic nodule versus FN have been described. In a hyperplastic nodule, follicular cells may form large, single-layer sheets. Within these sheets of follicular cells, there are well-formed macro follicles that of ten demonstrate perifollicular fibrosis or are surrounded by basement membrane-like material. Follicular cells within follicles are cohesive and often are "held" together by basement membrane and/or matrix material. Conversely, FN often has syncytial clusters of follicular cells, 3-dimensional groups, and loosely cohesive follicles (especially micro follicles) and has isolated, intact follicular cells. The follicles generally have a clean background, i.e., there is no obvious basement membrane or matrix-like material associated with them. The nuclei of follicular cells in FN often are enlarged [7].

The management of patients with a cytologic diagnosis of follicular neoplasm is a complex issue, and it is influenced by many factors. The prevalence of malignancy in this category reportedly ranges from $20 \%$ to $60 \%$ in the literature [9-11]. In our study the prevalence of malignancy in this category is $25.7 \%$, with $20 \%$ being follicular carcinoma and $5.7 \%$ being papillary carcinoma (false positive). The follicular variant of papillary carcinoma (FVPCT) is another source of error [7]. It is unavoidable that FNA diagnoses of FN will include some cases that prove to be FVPCT [7]. The key to distinguishing follicular neoplasm from FVPCT are the nuclear features, especially powdery chromatin and oval-shaped nuclei $[12,13]$. In our study, 2 cases diagnosed as follicular neoplasm proved to be papillary carcinoma, one being follicular variant of papillary carcinoma and the other an oncocytic variant.

There are several variants of papillary carcinoma, including the follicular variant, which may be wrongly diagnosed as follicular neoplasm. This is due to the fact that the nuclear changes of papillary carcinoma may be slight or focal, and also because features such as nuclear groove may be seen in other lesions, particularly in low-cellular smears [14]. Minimal cellularity of FNA specimens may lead to an erroneous diagnosis of nodular goiter in a case that is actually a papillary carcinoma [6]. This has management implications because an FNA diagnosis of follicular neoplasm or malignancy will necessitate surgery where as a benign lesion by FNA can be managed conservatively [7]. In our study, 2 cases reported as nodular goiter by FNA were papillary carcinoma by final histology.

Furthermore, it is well known that malignancy can coexist with benign thyroid nodules. Thorough physical examination, multiple passes to get a representative sample from a nodule, and ultrasound-guided aspiration may reduce sampling errors $[15,16]$. Cystic changes may occur in neoplastic lesions, thus making it difficult to sample the solid portion of the tumor and in-turn causing malignancy to be missed. Ultrasound-guided aspiration will prove useful in such a situation. Large size of a nodule can also lead to sampling errors [14].

Another observation in this research is that there were two cases that were reported as follicular neoplasm that turned out to be chronic lymphocytic thyroiditis in histological examination. Thyroid follicular cells in chronic lymphocytic thyroiditis may show a mild to moderate degree of cellular atypia or hurtle cell metaplasia leading to erroneous diagnosis of Hurthle cell/follicular neoplasm [6].

\section{Conclusion}

a. The sensitivity of FNAC in diagnosing benign nodules is $92 \%$ and specificity is $71.6 \%$.

b. Sensitivity of FNA for diagnosis of neoplasm is $81.6 \%$. Specificity of FNA for diagnosis of neoplasm is $92 \%$.

c. Sensitivity of FNA for diagnosis of malignancy is $87.8 \%$. Specificity of FNA for diagnosis of malignancy is $98.2 \%$.

d. Cytological similarities between hyperplasic nodule and follicular neoplasm are a major source of error.

Thus, FNA is highly sensitive and specific in the diagnosis of thyroid nodules. Taking samples from different regions of the nodule and fulfilling the criteria for adequacy can decrease the false negative rate.

\section{References}

1. Werga P, Wallin G, Skoog L, Hamberger B (2000) Expanding role of fineneedle aspiration cytology in thyroid diagnosis and management. World J Surg 24(8): 907-912.

2. Amrikachi M, Ramzy I, Rubenfeld S, Wheeler TM (2001) Accuracy of fine-needle aspiration of thyroid. Arch Pathol Lab Med 125(4): 484-488.

3. Del Rio P, Minelli R, Cataldo S, Ceresini G, Robuschi G, et al. (2011) Can misdiagnosis in pre-operative FNAC of thyroid nodule influence surgical treatment? J Endocrinol Invest 34(5): 345-348.

4. Crowe A, Linder A, Hameed O, Salih C, Roberson J, et al. (2011) The impact of implementation of the Bethesda System for Reporting Thyroid Cytopathology on the quality of reporting, "risk" of malignancy, surgical rate, and rate of frozen sections requested for thyroid lesions. Cancer Cytopathol 119(5): 315-321.

5. Auger M, Nayar R, Khalbuss WE, Barkan GA, Benedict CC, et al. (2013) Implementation of the Bethesda System for Reporting Thyroid Cytopathology: observations from the 2011 thyroid supplemental questionnaire of the College of American Pathologists. Arch Pathol Lab Med 137(11): 1555-1559.

6. Hajmanoochehri F, Rabiee E (2015) FNAC accuracy in diagnosis of thyroid neo plasms considering all diagnostic categories of the Bethesda reporting system: A single-institute experience. J Cytol 32(4): 238-243. 
7. Yang J, Schnadig V, Logrono R, Wasserman PG (2007) Fine-needle aspiration of thyroid nodules: a study of 4703 patients with histologic and clinical correlations. Cancer 111(5): 306-315.

8. LiVolsi VA, Baloch ZW (2004) Follicular neoplasms of the thyroid: view, biases, and experiences. Adv Anat Pathol 11(6): 279-287.

9. Deveci MS, Deveci G, LiVolsi VA, Baloch ZW (2006) Fine-needle aspiration of follicular lesions of the thyroid. Diagnosis and follow-Up. Cytojournal 3: 9 .

10. Baloch ZW, Livolsi VA (2002) Follicular-patterned lesions of the thyroid: the bane of the pathologist. Am J Clin Pathol 117(1): 143-150.

11. Miller B, Burkey S, Lindberg G, Snyder WH, Nwariaku FE (2004) Prevalence of malignancy within cytologically indeterminate thyroid nodules. Am J Surg 188(5): 459-462.

12. Sidawy MK, Del Vecchio DM, Knoll SM (1997) Fine-needle aspiration of thyroid nodules: correlation between cytology and histology and evaluation of discrepant cases. Cancer 81(4): 253-259.
13. Renshaw AA (2002) Focal features of papillary carcinoma of the thyroid in fine-needle aspiration material are strongly associated with papillary carcinoma at resection. Am J Clin Pathol 118(2): 208-210.

14. Renshaw A (2003) Misclassification of cytologic diagnoses in patients with follicular lesions or follicular neoplasms of the thyroid gland. Cancer 99(5): 318-320.

15. Ceresini G, Corcione L, Morganti S, Milli B, Bertone L, et al. (2004) Ultrasound-guided fine-needle capillary biopsy of thyroid nodules, coupled with on-site cytologic review, improves results. Thyroid 14(5): 385-389.

16. Baloch ZW, Tam D, Langer J, Mandel S, Li Volsi VA, et al. (2000) Ultrasound-guided fine-needle aspiration biopsy of the thyroid: role of on-site assessment and multiple cytologic preparations. Diagn Cytopathol 23(6): 425-429.

\begin{tabular}{ll}
\hline $\begin{array}{l}\text { BIOMEDICAL } \\
\text { RESEARCHES }\end{array}$ & Assets of Publishing with us \\
& - Global archiving of articles \\
\hline
\end{tabular}

